\title{
Analysis Application of the Space Forming Elements in The Interior Lobby at Aryaduta Hotel Jakarta
}

\author{
Elvi Livia $^{1 *}$ Ika Yuni $^{2}$ Fivanda Fivanda ${ }^{1}$ \\ ${ }^{1}$ Interior Design Study Program, Faculty of Art and Design, Tarumanagara University, Jakarta, Indonesia \\ ${ }^{2}$ Interior Design Study Program, Faculty of Art and Design, Jakarta Institute of Arts, Jakarta, Indonesia \\ ${ }^{*}$ Corresponding author.E-mail: elvi.615170018@stu.untar.ac.id
}

\begin{abstract}
Jakarta is one of the cities in Indonesia which is the center of the economy in Indonesia, such as the tourism industry, one of which is hotels. The hotel is a means of accommodation for both residents and tourists. A hotel is a type of accommodation that is commercially managed by using part or all of the existing building to provide the service facilities provided for guests and the general public who wish to stay. Interior design is a system in designing space and layout in a building. In an interior design, there are several elements that makeup space which is the basis for its formation. The elements that make up the interior space are a very important element in the interior. The room is a place for people to carry out an interaction that has an impact on action and reaction. Human actions and reactions can be influenced by the elements that make up space, a space forming element can create an atmosphere in the room. The existence of a person in a room can make a relationship between humans and all aspects of the surrounding environment. The method used is a descriptive method with a qualitative approach.
\end{abstract}

Keywords: Space forming elements, Hotel, Interior

\section{INTRODUCTION}

The economy in Indonesia is currently increasingly advanced and has an impact on the tourism industry sector, this progress does not only occur in the demand segment which is driven by rampant business activities. One of them is in Jakarta. It can be said that Indonesia also depends on the tourism sector to support its economy and development. The tourism industry in Indonesia is quite developed, one of which is hotels.

Jakarta is one of the cities in Indonesia which is the center of the economy in Indonesia. Jakarta is a support for the business world and tourism world in the city which is growing increasingly dynamic. It is hoped that with the construction of this hotel facility, the tourism sector in Jakarta can be more advanced. Jakarta is an attractive tourist destination for Indonesian citizens and foreign nationals.

A hotel is a company that is managed by its owner by providing food, beverage, and bedroom facilities to people who are traveling and able to pay a reasonable amount by the services received without any special agreement [3].

The lobby is the main part that becomes the face of the hotel. A lobby should be designed in a space that can connect visually and physically to a recreational area. The interior space is formed by several two-dimensional planes, namely the floor, walls, and ceiling.
Space-forming elements in the interior are elements or elements that are indispensable in an interior. If one of these elements is missing, the room cannot function and be used properly.[8]

Interior design is a system in designing space and layout in a building. In an interior design, several elements make up space which is the basis for its formation.

Interior design is the layout planning and interior design of a building. Its physical state fulfills our basic needs for shelter and protection, influences the shape of our activities and aspirations in expressing the ideas that accompany our actions, an interior design also influences our outlook, mood, and personality. Therefore, the purpose of interior design is the development of functions, aesthetic enrichment, and psychological enhancement of interior spaces [1]. Writing this paper aims to implement a space forming element in the good interior of the Aryaduta Jakarta Hotel Lobby. In an interior design, several elements form the basis of its formation. The forming elements are as follows:

\section{Floor elements}

The floor element is the lower part of a room that functions to support activities carried out in a room. The floor is an interior area that is flat and has a flat base, as a base area that supports interior activities of existing furniture. So, the floor to be used must have a strong, sturdy, and safe structure. Usually, this floor element consists of several sub-floors such as a place to hide pipelines, cables, and 
other utilities as supports. The floor also has a different psychological impact depending on the material applied. Floors that can be used are granite, marble, ceramic, and so on, which give the room a cool impression.

\section{Wall elements}

Walls are vertical structural planes that are usually solid in shape and are used to limit an area or room. Walls are an essential element for every building. It can be said that the wall is the main element that can form an interior space with the floor and ceiling area. The wall can also be used as a barrier or barrier with the room next to it. To maintain privacy for users.

The space forming element on the wall is an interior element in the middle that is between the ceiling and floor. The vertical structure plane is an important element that exists in a building. This element has a function as a forming or separator in a room. This room-forming element in the form of a wall can also be shaped as desired. The elements that form this interior space are 3 main types of walls, namely building walls, dividing walls or partitions, and retaining walls or bearing walls. In its construction, the walls have structural and finishing elements.

\section{Ceiling elements}

The ceiling is an important element in interior design. Even though it is beyond the reach of the hand, the ceiling plays an important visual role in the formation of interior spaces. This ceiling is an upper element that forms the boundary between the lower part of the room and the upper part. In general, ceiling heights ranging from $2.8 \mathrm{~m} 2-4 \mathrm{~m} 2$ or shorter and higher can be adjusted to the interior design that will be applied.

This space forming element in the form of a ceiling functions for electrical installation cables and ceiling structures. So that it can make the room more attractive and beautiful. The ceiling can be designed in various shapes depending on the interior design you want to apply. Can play the ceiling so that it produces interesting visuals. This is very important in the formation of interior spaces. Besides, this ceiling or ceiling also serves to withstand heat from outside. So that the air entering the room can be more controlled. The ceiling also has a function as an acoustic room.

\section{METHODS}

The method used in this paper is a descriptive method with a qualitative approach, namely adjusting the design to the literature theory. This qualitative descriptive analysis method by analyzing, describing, and summarizing a condition from the various data that has been collected [5]. This research method aims to describe the application of space-forming elements in the interior of Hotel Aryaduta Jakarta. Collecting data using literature from several books and journals, browsing from the internet, and everything related to hotel design and the elements of space forming elements that are applied to hotel interior design.
The data collection process is carried out by making observations to collect data related to hotels and searching the internet for data related to Hotel Aryaduta.

\section{FINDINGS AND DISCUSSION}

\subsection{Design Objects and Location Data}

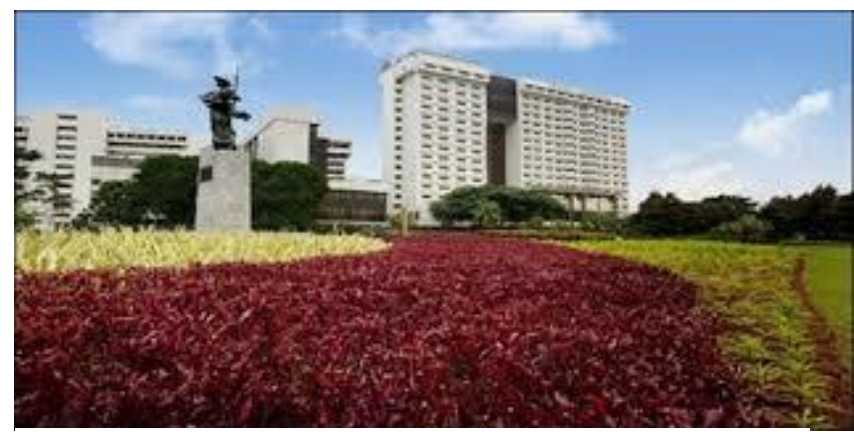

Figure 1 The façade of the hotel building aryaduta Jakarta (google.com)

Hotel Aryaduta Jakarta is located in a strategic location in the center of Jakarta, namely: Jl. Soldier KKO Usman Dan Harun, Gambir District, Central Jakarta, Special Capital Region of Jakarta 10110.

\subsection{Space Forming Elements}

Space is an infinite three-dimensional form because objects and events have relative positions and directions. Space can also have an impact on human behavior and culture, become an important factor in architecture, and will have an impact on the design of buildings and structures. Space has length, width, and height, shape, surface, orientation, and position. A plane that is developed (according to direction, apart from what already exists) turns into space. As a three-dimensional element in the architectural design repertoire, space can be solid. In this case, the space that is inside or limited by the plane will be moved by mass or empty space [8].

The elements that make up the interior space include floors, walls, and ceilings. Each factor can be broken down in more detail based on:

- Line

Each line evokes an emotional response and conveys a different feeling. A few points regarding line effects in the design and layout of the room are as follows:

- Vertical lines can give a feeling of dignity, formality, and cause the eyes to move upwards, thus adding to visual beauty.

- The horizontal line is the calmest and most stable of all line shapes. The eye can move from side to side along a horizontal line, expanding the area or object being seen.

- Shape

Everything has a form. The shape is anything that has a diameter, height, and width. The basic shapes known to people are squares, circles, and triangles. The shape can 
reflect the physical state of an object. Such as detailed drawings of humans, animals, or other objects.

In relation to the environment, forms can be boring or even interesting. It is important to use them creatively to make sure the shape complements the ambiance and design of the space. Man-made shapes are often geometric and more symmetrical whereas organic shapes are found naturally and are more asymmetrical.

- Color

The use of color in the design of a space can have a psychological effect on the user. Color can have a certain psychological effect on someone who sees it. In the interior, all colors can give a different impression to space.

Color also has a very important role in creating an atmosphere of space. The combination of colors used in a space creates a livelier and less boring atmosphere [6]. Color can provide/create an atmosphere and emotional effect [4]. Complex colors can present a cheerful character and a space atmosphere that inspires creativity [9].

- Texture

The texture is the specific quality of an initiation produced by the tri-matrix structure. [1] The texture is a feel, appearance, or surface consistency or substance, this texture also has something to do with the material used. The texture is often used to clarify the smoothness or roughness of a surface. Textures can also be used to clarify the surface quality characteristics of existing materials. such as roughness in stone materials, wood grain, and so on. And the texture in a space can also provide an atmosphere in the space like a stone will give a natural atmosphere. Light, thin, and smooth textures give the impression of a bigger space. Wood material that will make the room warmer.

- Material

The material used will affect the formation of the atmosphere of space [6], including:

a. Floor :

Floor covering materials that can provide a warm atmosphere, such as carpets, parquet, and so on. Floor covering materials that provide a cool/cool atmosphere, such as marble, natural stones, ceramics, and so on.

- Marble material has permanent characteristics. The use of marble as a floor covering provides a beautiful, cool, and comfortable atmosphere.

- Ceramic tile material has characteristics that are beautiful, cool, and wide.

- Wood materials, such as parquet, have natural characteristics, gives a warm and comfortable impression to space.

b. Wall :

- Stone : There are various kinds of stones. There are natural stones, river stones, bricks, and others. This stone material can give the impression and atmosphere that feels like an approach to beautiful nature, and create a comfortable and warm atmosphere.

- Paint : The use of paint as a wall covering gives a clean, spacious, and neat atmosphere depending on the color used. The use of paint on walls has the advantage that it is more practical and economical, as well as durable.
- Metal : This material can give an elegant and luxurious impression to space.

- Glass : Mirrors and glass provide a beautiful and modern atmosphere, can make the room more spacious and bright.

- Wood : have natural characteristics, are soundproof, durable, and are a good conductor of warmth. Which creates a warm, natural and beautiful atmosphere.

c. Ceiling :

Materials that can be used as ceilings are various, such as wood, gypsum, metal, and so on. This gypsum can provide a neat, clean, and simple atmosphere. Gypsum is a lightweight and flexible material, presenting a simple and simple impression. the use of metal has the advantage that it is strong and durable and gives an elegant appearance. ceiling with wood material gives a natural and luxurious impression. is a good acoustic and able to keep the room temperature warm.

\subsection{Application of The Space Forming Elements}

\subsubsection{Floor}

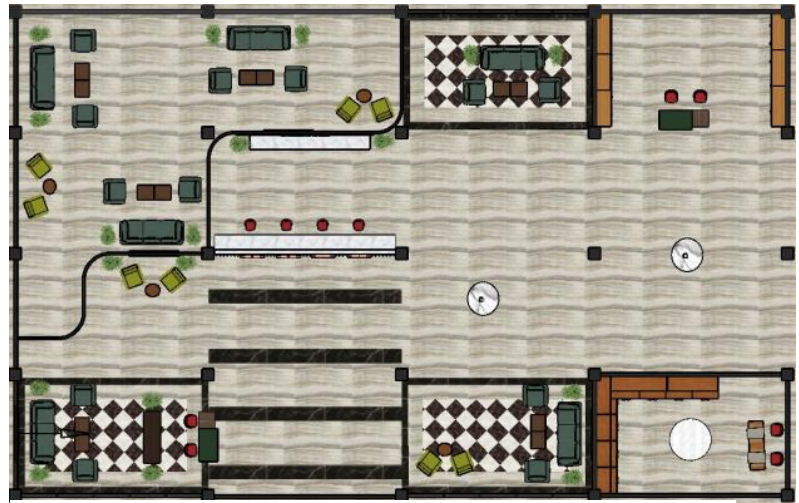

Figure 2 Floor plan aryaduta hotel lobby Jakarta (Elvi Livia, 2020)

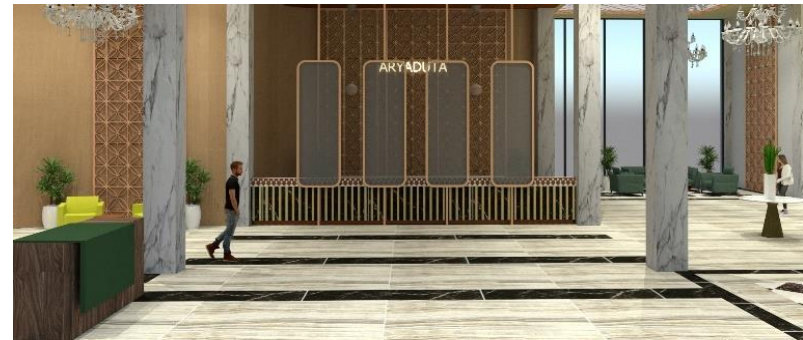

Figure 3 Examples of applying floor space forming elements to the lobby area (Elvi Livia, 2020) 


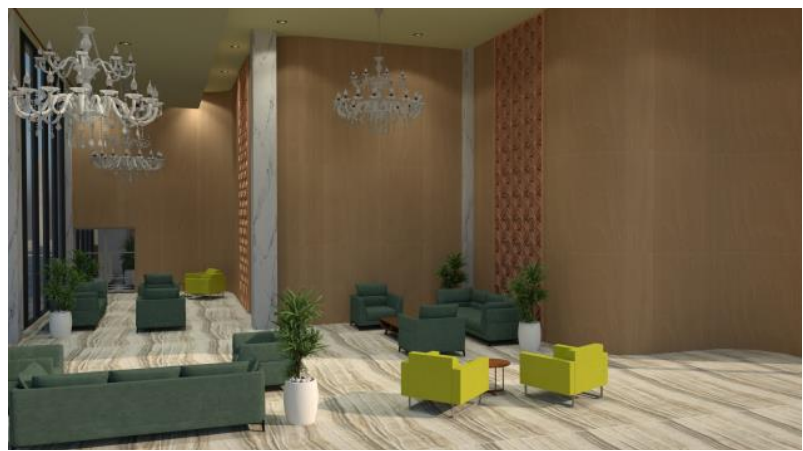

Figure 4 Examples of applying floor space forming elements to the lobby in the lounge area (Elvi Livia, 2020)

As seen in the picture above, the floor elements give an elegant impression to the room by applying the materials used.

The use of marble tile material provides a beautiful and comfortable atmosphere [6].

The color used on this floor is a combination of white, black, and cream. The white color in the room can give a clean and spacious impression in a room, white also symbolizes modern style [9]. While the use of black creates an atmosphere that can instill trust, the meaning of the color black is often referred to as a symbol of protection. The use of cream colors as floor colors is perfect for rooms that want to create a warm atmosphere. This color is also not flashy so it can create a calm and comfortable atmosphere. The use of horizontal lines and directions on the lobby floor creates a calm feeling in the room. The geometric shapes used, especially the rectangular shape, have stable properties.

Analysis of the application of elements forming space (floor) Aryaduta Hotel Lobby Jakarta:

The floor on the Lobby of Hotel Aryaduta Jakarta uses marble tile floor material which gives a beautiful and comfortable atmosphere. And based on the materials, colors, lines, and shapes, it can be said that the floors at the Lobby of Hotel Aryaduta Jakarta can give an elegant, modern, calm, and comfortable impression in the room, thus creating a familiar, calming, healing and relaxing atmosphere in the space [7]. The choice of white color on the floor as an accent on floor elements is also considered very suitable because it serves as a visual break so that the room does not feel full of color.

\subsubsection{Wall}

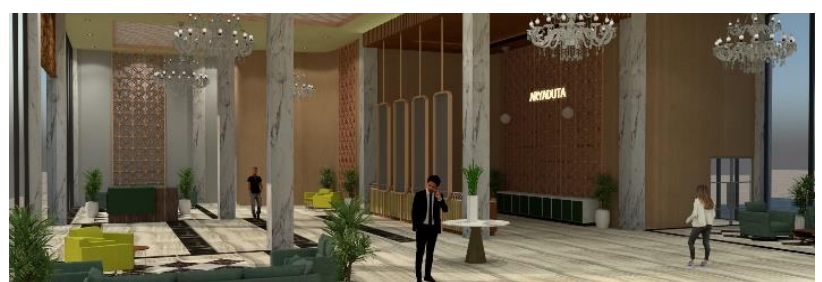

Figure 5 Examples of application of space-forming elements in the lobby wall area (Elvi Livia, 2020)

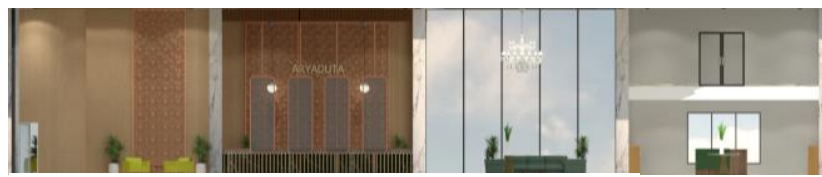

Figure 6 View of wall a in the lobby area (Elvi Livia, 2020)

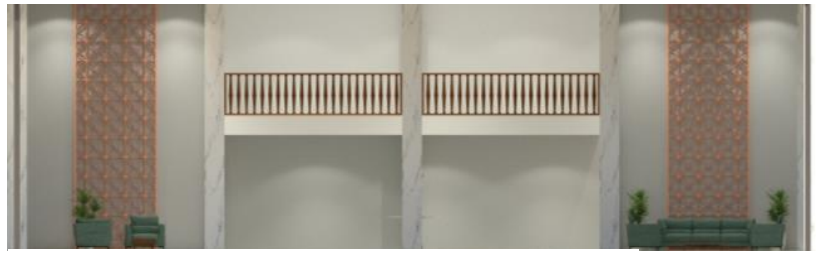

Figure 7 View of wall b in the lobby area (Elvi Livia, 2020)

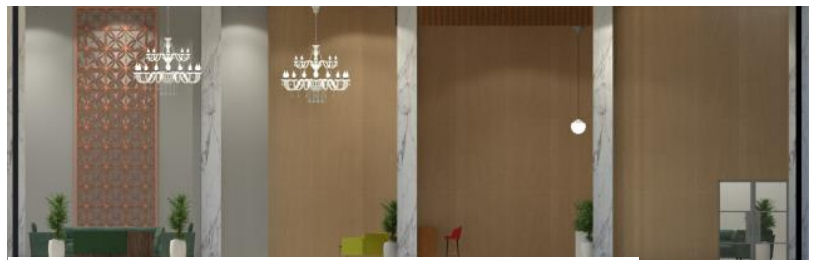

Figure 8 View of wall c in the lobby area (Elvi Livia, 2020)

In the wall element, which displays a simple design but still exudes a warm atmosphere from the coloring which is dominated by brown, especially on the partitions, with the addition of other colors that can support the aesthetics of the space such as metal as wall decoration.

The use of paint materials as wall coverings gives a clean, spacious, and neat atmosphere depending on the color used [6]. Ornamental forms on the receptionist backdrop and several other areas as accents use metal which gives an elegant and luxurious impression. In some areas of the walls, especially on partitions, use wood material that has natural characteristics, is soundproof, durable, and a good warm conductor which can create a warm, natural, and beautiful atmosphere in a space. The use of glass is also used to provide a beautiful and modern atmosphere, and to make the room wider and brighter with the incoming natural light.

The colors used are gray, brown, and gold. Gray color itself can provide serenity and balance in a room, brown is a color that can warm the atmosphere and give a comfortable impression to the room, gold is a color that gives a luxurious impression.

There is use of vertical lines that can give a sense of dignity and formality and make the eye more drawn to the visual space.

The use of geometric shapes on the walls of the lobby area, especially the rectangular shape, has stable properties.

Analysis of the application of the elements forming the space (wall) Aryaduta Hotel Lobby Jakarta:

The wall elements that are applied to the lobby with the material used are dominated by the paint used as a wall covering which gives a clean, spacious, and neat 
atmosphere. The walls in the Lobby use paint material with several other materials such as metal and wood. Then the colors used are gray, brown, and gold with a good color play. The existence of glass walls makes the room seem spacious and airy and brighter. The impression of being spacious and airy supports the comfort of visitors to do activities in it.

\subsubsection{Ceiling}

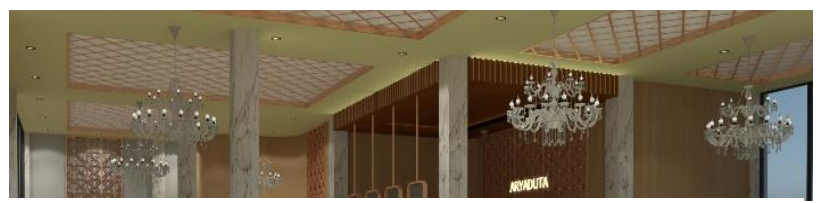

Figure 9 Examples of applying ceiling forming elements to the lobby area (Elvi Livia, 2020)

On the ceiling in the lobby area, you can see a dominating yellow paint finish with accents with the use of laser metal cutting and wood on the reception ceiling area. The simple appearance but with the addition of this accent makes the ceiling more attractive.

The materials used are gypsum, metal, and wood. Gypsum material can provide a neat, clean, and simple atmosphere [6]. The use of metal gives an elegant and luxurious impression. Wood material has natural characteristics, is soundproof, durable, and a good conductor of warmth. Which creates a warm, natural and beautiful atmosphere. The colors used are yellow and a touch of gold and brown. Gives a brighter impression and is considered broader than it is. The dominant yellow color application on the lobby ceiling gives a warm feel and can motivate and improve one's mood. The color yellow can also provide positive energy, which can relieve anxiety and give an uplifting impression. The use of brown is also a color that can warm the atmosphere and give a comfortable impression to the room. As well as the use of gold which makes the room look luxurious.

The existence of a horizontal line creates a feeling of calm and the direction of the horizontal line also describes calm, as well as the presence of a line vertical gives a feeling of dignity, is formal and causes the eyes to move upwards, thus adding to visual beauty.

The shape on the ceiling is with the up ceiling and down ceiling which is used as accents in the ceiling form game.

Analysis of the application of the room-forming elements (ceiling) Aryaduta Hotel Lobby Jakarta:

This ceiling as a whole is good enough. Starting from the material used is gypsum material which can provide a neat, clean, and simple atmosphere [6]. The use of metal gives an elegant and luxurious impression. Wood material has the characteristics of natural, soundproof, durable, and a good conductor of warmth. Until the colors used are well combined. Which gives the impression of being comfortable, warm, and beautiful.

\section{CONCLUSIONS}

In designing the interior of Hotel Aryaduta Jakarta, it is hoped that it can give a new atmosphere to a hotel. The design of the lobby itself is the main part that becomes the face of the hotel. So a lobby should be designed in a room that can be connected well visually.

Visual beauty, quality, and space facilities that support comfort and meet the needs of visitors. It can be seen from the many colors plays on the elements that make up the interior space that make the lobby look more beautiful and attractive, supporting the comfort of visitors to Hotel Aryaduta Jakarta.

The application of space-forming elements to the interior plays an important role in the design of a building, especially the lobby. The interior is formed not only from visual beauty but from the atmosphere of the room that gives visitors a comfortable impression. By applying elements that form an attractive interior space, it is hoped that visitors will get a good first impression of the lobby appearance.

\section{REFERENCES}

[1] C. DK. Francis, Interior Design Illustration, Jakarta: Erlangga, 1996.

[2] C. Ayhwien, The Influence of Accessories and Space-Forming Elements on the Atmosphere and Character of the Lobby of Hotel Artotel Surabaya. Journal Intra Vol. 1, No. 1, 1-7, 2013.

[3] Hotel Proprietors Act (Liabilities and Rights), United Kingdom Legislation, 1956.

[4] T. Hartman, The Color Code, California, 1987.

[5] I M. Winartha, Quantitative and Qualitative Research Methodology. Yogyakarta: Graha Ilmu, 2006.

[6] J. P. Suptandar, Interior Design: An Introduction to Interior Planning for Design and Architecture Students, Jakarta: Djambat, 1999.

[7] S. Wirania, Home Interior Color Inspiration, Jakarta: Griya Kreasi, 2010.

[8] Wicaksono and Tisnawati, Basic elements of the interior, Jakarta: Creation house, 2014.

[9] J. E. Widyartamti, Color Harmonies, Jakarta: PT. Gramedia Printing, 2010. 